\title{
Nutritional knowledge and nutritional status amongst university students
}

\author{
Ritu Priya ${ }^{1 *}$, Mukul Sinha ${ }^{2}$ \\ ${ }^{1}$ Guest Faculty, ${ }^{2}$ Associate Professor, Dept. of Food and Nutrition, Ex PG student of RPCAU, Dr. Rajendra Prasad Central Agricultural \\ University Samastipur, Bihar, India
}

*Corresponding Author: Ritu Priya

Email: priya.ritu19@gmail.com

\begin{abstract}
Nutrition knowledge is defined as knowledge of concepts and process related to nutrition and health. It includes knowledge of diet and health, diet and disease, foods representing major source of nutrients, dietary guidelines and recommendations. It plays an important role in raising awareness and ultimately health of society. The study was conducted among 60 students (30 boys and 30 girls) from all colleges of RPCAU who were residing in University hostel and studying in seventh semester. In order to extract relevant information a schedule was developed for personal interview. It was pretested before the start of the research work. For testing the nutritional knowledge, 138 questions related to nutrition impacting health were asked through developed interview schedule. To assess the nutritional status anthropometric and clinical examination were evaluated by personal meeting. Haemoglobin level was estimated by Sahli's method through expert lab technician. Significant difference in the knowledge level between boys and girls was observed. Knowledge level of girls was better in comparison to boys. Majority of both boys (86.66\%) and girls (63.33\%) were within normal BMI range. Among girls there was the case of underweight $(23.33 \%)$ and overweight $(13.34 \%)$. Though the percentage of underweight and overweight was opposite to the girls among boys, still there was a vast difference between underweight percentage of girls (23.33\%) and boys(3.33\%). majority of male and females students $(28.33 \& 26.66 \%)$ having haemoglobin level in the range of $10-12 \mathrm{~g} / \mathrm{dl}$ followed by 21.66 percent of male comes in the range of $12-16 \mathrm{~g} / \mathrm{dl}$. In case of female students, 21.66 percent having haemoglobin level in the range of $8-10 \mathrm{~g} / \mathrm{dl}$ and $1.66 \mathrm{percent}$ in the range of $6-8 \mathrm{~g} / \mathrm{dl}$. Correlation was found between nutritional knowledge and haemoglobin level of the students. Boys were having less nutrition knowledge that clearly showed negative impact on their health. Hence, it recommended that the knowledge of nutrition is utmost important for all.
\end{abstract}

Keywords: Nutritional knowledge, Nutritional status, Anthropometric, Hemoglobin, BMI.

\section{Introduction}

Nutrition knowledge is defined as knowledge of concepts and process related to nutrition and health. It includes knowledge of diet and health, diet and disease, foods representing major source of nutrients, dietary guidelines and recommendations. It plays an important role in raising awareness and ultimately health of society.

It has been shown to play an important role in influencing healthy food habits which ensure nutrient needs throughout lifecycle are met adequately since individual needs are determined by rate of growth. Nutrition status of an individual is a result of interrelated factors influenced by quality and quantity of food consumed and the physical health. ${ }^{1}$ Kolodinsky, Harvey-Berino, Berlin, Johnson, \& Reynolds (2007) found increased knowledge of dietary guidelines to be positively related to healthier eating practices among college students. The authors concluded that healthy eaters have a higher nutritional knowledge leading to good food choices which can promote weight reduction and maintenance of healthy weight. This study is also supported by the finding of ${ }^{2}$ Huang, Harris, Lee, Nazir, Born, \& Kaur, (2003) who suggested that having the knowledge to make the right choices is important in establishing good eating habits at an early age.

Anthropometric indices indicate cumulative effect of quality and quantity of food as well as other health factors. University students are at transition age period from adolescence to adulthood, where their growth and maturity would complete at such age range. At this transition period, the interaction of various biological, intellectual, psychological and social factors contribute towards the formation of personal identity. In addition nutrition too has great impact in the development of personality.

Nutritionally deprived persons have smaller body size as well as weight, and they expend energy only in proportion to their body weight. Thus, short stature and reduced body size due to under -nutrition will mean lower levels of productivity for sustained moderate to heavy physical work. Work efficiency is also directly correlated with energy consumption. Restricted energy intake leads to reduction in energy expenditure, which may limit work capacity. At present time, when more focus has been given on taking balance diet or proper nutrition, still university students do not apply this knowledge on themselves even though it is gained during school/ college days or from family eating habits. There may be many reasons like stress, work load, maintenance of body weight and images etc due to which it may be difficult to practice it in their daily life. At hostel, boys and girls student get food either from canteen or mess. Foods available at canteen are usually cooked in unhygienic condition and usually during the process of cooking most of the essential nutrients are destroyed and therefore may not fulfill the requirement of students. This may results in malnutrition. The most crucial time of the life when obesity develops easily is college years.

Developing countries like India are encountering dual burden of under- nutrition and over-nutrition. According to an article published in 3 "Times of India"(April,2016),India ranks first place in terms of prevalence of under nutrition 
and $5^{\text {th }}$ place in terms of over nutrition. The aim of this study was to assess the nutritional knowledge of the university boys and girls and investigate whether there is significant correlation between nutritional knowledge and nutritional status among students of Dr. Rajendra Prasad Central Agricultural University.

\section{Materials and Methods}

The study was conducted among 60 students (30 boys and 30 girls) from all colleges of Dr.RPCAU who were residing in University hostel and studying in seventh semester. In order to extract relevant information an interview schedule was developed and was subjected to pretesting before starting the research work. For testing the nutritional knowledge 138 questions related to nutrition impacting health were asked through developed interview schedule. To assess the nutritional status anthropometric and clinical examination were evaluated by personal meeting and haemoglobin level was estimated by Sahli's method done through expert lab technician. A normal haemoglobin level is at $14 \mathrm{gm} / \mathrm{dl}$ for males and $12 \mathrm{gm} / \mathrm{dl}$ of blood for females. (Source: - ${ }^{4}$ Shubhangini A Joshi. Nutrition \& Dietetics with Indian case studies)

In anthropometric measurement height was measured with the help of non stretchable tape, weight was taken with the help of digital weighting machine and BMI was calculated as weight in kilograms divided by height in square meter $\left(\mathrm{kg} / \mathrm{m}^{2}\right)$.

BMI $=$ Weight $(\mathrm{kg}) /$ Height $\left(\mathrm{m}^{2}\right)$
BMI classification of Body Mass Index (BMI)

\begin{tabular}{|l|c|c|}
\hline \multicolumn{1}{|c|}{ Based on BMI } & $\begin{array}{c}\text { Body Index } \\
\mathbf{K g} / \mathbf{m}^{\mathbf{2}}\end{array}$ & $\begin{array}{c}\text { Health risk } \\
\text { associated }\end{array}$ \\
\hline Under weight & Below 18.5 & Low \\
\hline Normal weight & $18.5-25.0$ & Moderate \\
\hline Overweight & $25.1-29.1$ & High \\
\hline Obesity & 30 above & Very high \\
\hline
\end{tabular}

(Source: ${ }^{5}$ Sutra (2005) Food and Nutrition World, Institute of Science Bangalore)

The data was entered in Microsoft Office Excel and statistical analysis was done using SPSS 16 software. Mean \pm SD, frequency, percentage, correlation and t-test were calculated for selected variables. A p-value of $<0.05$ and $<0.01$ was considered to be statistically significant.

\section{Results \\ Nutritional knowledge of the subjects}

In this study total 60 students were participated actively in which 50 percent students having low level of nutritional knowledge followed by 40 percent come under medium level and 10 percent comes under high level of nutritional knowledge. Mean and standard deviation of nutritional knowledge of boys and girls is shown in table. t-test show that there is significant difference in the knowledge level between boys and girls. Knowledge level of girls was good than boys student. This finding is similar to the study of ${ }^{6}$ Labhan L (2016). Study was conducted among Syrian University students and female students were found slightly higher points in nutrition knowledge score.

Table 1: Nutritional knowledge of the subjects

\begin{tabular}{|c|c|c|c|}
\hline Particulars & & \multicolumn{2}{|c|}{ Subjects( N= 60) } \\
\hline Score & Level & Frequency & Percentage \\
\hline 75 & Low & 30 & 50 \\
\hline $76-103$ & Medium & 24 & 40 \\
\hline $104-138$ & High & 6 & 10 \\
\hline
\end{tabular}

Table 1.1: Nutritional knowledge of boys and girls

\begin{tabular}{|c|c|c|c|c|c|c|}
\hline Particulars & & \multicolumn{4}{|c|}{ Subjects( N= 60) } & \\
\hline & & \multicolumn{3}{|c|}{ Boy } & \multicolumn{2}{c|}{ Girl } \\
\hline Score & Level & Frequency & Percentage & Frequency & Percentage & Percentage \\
\hline 75 & Low & 21 & 70 & 9 & 30 & 30 \\
\hline $76-103$ & Medium & 9 & 30 & 15 & 50 & 50 \\
\hline $104-138$ & High & - & - & 6 & 20 & 20 \\
\hline
\end{tabular}

Table 2 Comparison of nutritional knowledge between boys and girls

\begin{tabular}{|c|c|c|c|}
\hline & Mean \pm SD(Boy) & Mean \pm SD(Girl) & Difference(t-test) \\
\hline Nutritional knowledge & $67.23 \pm 17.60$ & $85.83 \pm 17.57$ & $3.651^{* *}$ \\
\hline
\end{tabular}

${ }^{* *}$ Correlation is significant at the 0.011 evel

\section{Nutritional status of the subjects}

$\mathrm{BMI}$ is the parameter used to denote person's ideal weight, underweight, overweight and obese. It can be observed from table 3 that 75 percent of students having BMI in the range of 18.5-25(Normal), 13.66 percent of students having BMI below18.5 (Underweight), 11.66 percent were in the range of 25.1-29.9(Overweight).None of the student comes under the BMI range 
greater than 30(obesity).This finding is similar to result of ${ }^{7}$ Karmakar et al.(2016), ${ }^{8}$ Elhisadi TA and Flailih AM.S(2015), ${ }^{9}$ Mani Geetha.(2014). Table 3.1 indicates that majority of both boys $(86.66 \%)$ and girls $(63.33 \%)$ were within normal BMI range followed by underweight $(23.33 \%)$ and overweight in girls. Though the percentage of underweight and overweight was opposite to the girls among boys, still there was a vast difference between underweight percentage of girls (23.33\%) and boys (3.33\%). This may happen because girls are more conscious about their health in comparison to boys. The present study contradicts the report of ${ }^{10}$ Pengid S and Pelzar K (2015) who reported that more of male students to be overweight and obese than female students of Thailand University.

Table 3: BMI of students

\begin{tabular}{|c|c|c|}
\hline BMI(kg/m2) & Frequency & Percentage \\
\hline Below 18.5 & 8 & 13.66 \\
\hline $18.5-25$ & 45 & 75 \\
\hline $25.1-29.9$ & 7 & 11.66 \\
\hline 30 above & 0 & 0 \\
\hline
\end{tabular}

Table 3.1: BMI of students

\begin{tabular}{|c|c|c|c|c|c|}
\hline & \multicolumn{2}{|c|}{ Boy } & \multicolumn{2}{c|}{ Girl } & \\
\cline { 1 - 5 } BMI $\left(\mathbf{k g} / \mathbf{m}^{2}\right)$ & Frequency & Percentage & Frequency & Percentage & \\
\hline Below 18.5 & 1 & 3.33 & 7 & 23.33 & 23.33 \\
\hline $18.5-25$ & 26 & 86.66 & 19 & 63.33 & 63.33 \\
\hline $25.1-29.9$ & 3 & 10 & 4 & 13.33 & 13.33 \\
\hline 30 above & - & - & - & - & - \\
\hline
\end{tabular}

Table 4: Hemoglobin level of students

\begin{tabular}{|c|c|c|}
\hline & Frequency & Percentage \\
\hline Hemoglobin level(g/dl) & & \\
\hline $6-8$ & 1 & 1.66 \\
\hline $8-10$ & 13 & 21.66 \\
\hline $10-12$ & 33 & 55 \\
\hline $12-16$ & 13 & 21.66 \\
\hline
\end{tabular}

Table 4.1: Hemoglobin level of students

\begin{tabular}{|c|c|c|c|c|}
\hline \multirow{2}{*}{ Particulars } & \multicolumn{3}{|c|}{ Subjects(N= 60) } \\
\cline { 2 - 5 } & \multicolumn{2}{|c|}{ Boys } & \multicolumn{2}{c|}{ Girls } \\
\hline Hemoglobin level(g/dl) & Frequency & Percentage & Frequency & Percentage \\
\hline $6-8$ & - & - & 1 & 3.33 \\
\hline $8-10$ & - & - & 13 & 43.33 \\
\hline $10-12$ & 17 & 56.66 & 16 & 53.33 \\
\hline $12-16$ & 13 & 43.33 & - & - \\
\hline
\end{tabular}

Table 4 describes that 55 percent student having the Hemoglobin level between 10-12g/dl, 21.66 percent students were in between $12-16 \mathrm{~g} / \mathrm{dl}$ and $8-10 \mathrm{~g} / \mathrm{dl}$ only 1.66 percent students fall in between $6-8 \mathrm{~g} / \mathrm{dl}$ Hemoglobin level.

Table 4.1 shows that majority of male and females students $(28.33 \& 26.66$ percent) having haemoglobin level in the range of $10-12 \mathrm{~g} / \mathrm{dl}$ followed by 21.66 percent of male comes in the range of $12-16 \mathrm{~g} / \mathrm{dl}$. In case of females students 21.66 percent having haemoglobin level in the range of $8-10 \mathrm{~g} / \mathrm{dl}$ and 1.66 percent in the range of $6-8 \mathrm{~g} / \mathrm{dl}$. This finding shows similarity with result of ${ }^{11}$ Shill $\mathrm{KB}$ et al. (2014), study was conducted to find prevalence of Iron- deficiency anemia among university students. Students suffering from different types of vitamin deficiency disease. It is clear from the table that 10 percent of the students were suffering from pain \& sensation in the arm and legs, 6.66 percent students were suffering from angular stomatitis and bleeding gum followed by 3.33 percent of students were suffering from dry scaly dermatitis and 1.66 percent from cheilosis, goitre \& pitting edema. Correlation was found between nutritional knowledge and haemoglobin level of the students.

Table 5: Clinical Symptoms of subjects (present)

\begin{tabular}{|l|c|c|}
\hline Particulars & \multicolumn{2}{|c|}{ Subjects(N= 60) } \\
\hline Diseases & Frequency & Percentage \\
\hline Angular stomatitis & 4 & 6.66 \\
\hline
\end{tabular}




\begin{tabular}{|l|c|c|}
\hline Chelosis & 1 & 1.66 \\
\hline Dry scaly dermatitis & 2 & 3.33 \\
\hline Bleeding gum & 4 & 6.66 \\
\hline Goitre & 1 & 1.66 \\
\hline Anemia pitting oedema & 1 & 1.66 \\
\hline Pain \& sensation in the arm and leg & 6 & 10 \\
\hline
\end{tabular}

Table 6: Correlation coefficient between nutritional knowledge and hemoglobin level

\begin{tabular}{|l|l|}
\hline & $\mathrm{Hb}$ \\
\hline Nutritional knowledge & $.316^{*}$ \\
\hline
\end{tabular}

\section{Conclusion}

After the study of the samples it has been concluded that nutritional knowledge of the girls were better than boys and in terms of nutritional status boys were found more obese and anemic than girls. So, there is need to aware boys also through various programmes and different sources.

\section{Source of funding}

None.

\section{Conflict of interest}

None.

\section{References}

1. Kolodinsky J, Harvey- Berino JR, Berlin L, Jhonson RK and Renolds TW et al. Knowledge on current dietary guidelines and food choice by college students: better eaters have higher knowledge of dietary guidance. J Am Dietetics Assoc 2007;107(8):1409-13.

2. Huang T.K, Jo Harris K, Lee R.E, Nazir N, Born W. and Kaur $\mathrm{H}$ et al. Assessing Overweight, Obesity, Diet, and Physical Activity in College Students. J Am Coll Health 2003;52( 2):836.

3. "Times of India"(April,2016),

4. Shubhangini A Joshi. Nutrition \& Dietetics with Indian case studies)
5. Sutra. Food and Nutrition World, Institute of Science Bangalore). (2005)

6. Labban L. Nutrition knowledge assessment of Syrian university students. J Scientific Soc 42(2).

7. Karmakar P, Jahan N, Banik S, Das A, Rahman K.A, Kundu S.K.and Sattar M.M et al. Food Habits, Obesity and Nutritional Knowledge among the University Students in Noakhali Region of Bangladesh: A Cross Sectional Study. J Food Nutrit Dis 2016;5(4).

8. Elhisadi T.A and Flailih AM.S. Assessment of Body Mass Index (BMI) Among Girl Students Living In Hostel University In Derna-Libya. Canadian Open Public Health J 2015;2(1):17.

9. Geetha M. Assessment of Body Mass Index and its Associated Nutritional Factors Among Undergraduate Medical Students in Tamil Nadu, India: A Cross-Sectional Study. J Pioneer Med Sci 2014;4(3):137-42.

10. Pengid S. and Peltzer K. Prevalence of overweight and underweight and its associated factors among male and female university students in Thailand. HOMO - Jf Comparat Human Biol 2015;66:176-86.

11. Shill K.B, Karmakar P, Kibria G, Das A, Rahman A, Hossain $\mathrm{S}$ et al, Prevalence of Iron-deficiency Anaemia among University Students in Noakhali Region, Bangladesh. J Health Population Nutrit. 32(1):103-110.

How to cite: Priya R, Sinha M. Nutritional knowledge and nutritional status amongst university students. IP J Nutr Metab Health Sci 2020;3(1): 